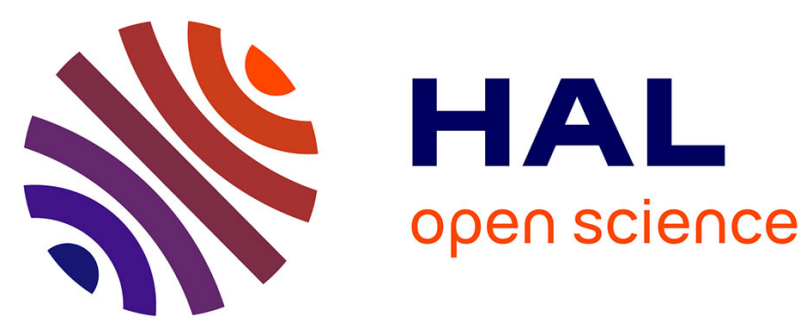

\title{
Mapping the Uniformity of Optical Microwires Using Phase-Correlation Brillouin Distributed Measurements
}

Desmond M. Chow, Joël Cabrel Tchahame, Andrey Denisov, Jean-Charles Beugnot, Thibaut Sylvestre, Lizhu Li, Raja Ahmad, Martin Rochette, Kenny Hey Tow, Marcelo A. Soto, et al.

\section{To cite this version:}

Desmond M. Chow, Joël Cabrel Tchahame, Andrey Denisov, Jean-Charles Beugnot, Thibaut Sylvestre, et al.. Mapping the Uniformity of Optical Microwires Using Phase-Correlation Brillouin Distributed Measurements. Frontiers in Optics, Oct 2015, San Jose, United States. 10.1364/FIO.2015.FW4F.4 . hal-01198799

\section{HAL Id: hal-01198799 \\ https://hal.science/hal-01198799}

Submitted on 3 Oct 2017

HAL is a multi-disciplinary open access archive for the deposit and dissemination of scientific research documents, whether they are published or not. The documents may come from teaching and research institutions in France or abroad, or from public or private research centers.
L'archive ouverte pluridisciplinaire HAL, est destinée au dépôt et à la diffusion de documents scientifiques de niveau recherche, publiés ou non, émanant des établissements d'enseignement et de recherche français ou étrangers, des laboratoires publics ou privés. 


\title{
Mapping the Uniformity of Optical Microwires Using Phase-Correlation Brillouin Distributed Measurements
}

\author{
Desmond M. Chow ${ }^{1}$, Joël C. Tchahame ${ }^{2}$, Andrey Denisov ${ }^{1}$, Jean-Charles Beugnot ${ }^{2}$, Thibaut Sylvestre ${ }^{2}$, \\ Lizhu Li ${ }^{3}$, Raja Ahmad ${ }^{3}$, Martin Rochette ${ }^{3}$, Kenny Hey Tow ${ }^{1}$, Marcelo A. Soto ${ }^{1}$, Luc Thévenaz ${ }^{1}$ \\ ${ }^{I}$ Institute of Electrical Engineering, Ecole Polytechnique Fédérale de Lausanne, 1015 Lausanne, Switzerland \\ ${ }^{2}$ Institut FEMTO-ST, Université de Franche-Comté, CNRS UMR 6174, Besançon, France \\ ${ }^{3}$ Department of Electrical and Computer Engineering, McGill University, Montreal (QC), Canada \\ Email: joelcabrel.tchahame@femto-st.fr
}

\begin{abstract}
The distributed Brillouin gain profile of an ultrathin optical microwire made of chalcogenide-glass is characterized using a phase-modulated correlation-domain measurement technique. Method resolves variations of uniformity below $5 \%$ along a $13 \mathrm{~cm}$-long microwire.

OCIS codes: (290.5900) Scattering, stimulated Brillouin, (060.2270) Fiber characterization
\end{abstract}

\section{Introduction}

Optical microwires are hair-like slivers of glass which can be manufactured by tapering optical fibers down to a few microns or less [1]. They have a large number of optical properties that make them very attractive for both fundamental physics and photonic technologies. In addition to providing strong light confinement and enhanced nonlinear optical effects [1,2], optical microwires also exhibit a large evanescent field, enabling applications not currently possible with conventional optical fibers. Although extensive studies of their optical properties have been reported [1,2], it still remains unclear whether these ultrathin fibers are really uniform and what are their diameter fluctuations.

In this work, a high-resolution distributed Brillouin sensing technique based on phase correlation is proposed to map the longitudinal profile of the Brillouin gain spectrum along a chalcogenide optical microwire. Experimental results correspond, to the best of our knowledge, to the first measurement of the local Brillouin gain spectrum as a function of the position inside an optical microwire. Results show very low Brillouin frequency shift (BFS) fluctuations along a $1.65 \mu \mathrm{m}$-diameter optical wire, implying an excellent geometrical uniformity.

\section{Experimental setup and results}

Figure 1(a) shows a schematic of the chalcogenide optical microwire. This consists of an $\mathrm{As}_{2} \mathrm{Se}_{3}$ glass core surrounded by a polymer (PMMA) cladding, drawn using the heat-brush technique [2]. The PMMA cladding makes the microwire robust to mechanical strain while preventing it from being damaged by the outside environment. The original core size in the untapered region is $16 \mu \mathrm{m}$, which has been reduced down to $1.65 \mu \mathrm{m}$ in a $13 \mathrm{~cm}$-long tapered region.

Figure 1(b) shows the experimental setup used to map the distributed BFS profile. The measurement principle is based on phase-coding of both the Brillouin pump and probe waves using a high frequency pseudo-random bit sequence (PRBS) [3]. Since pump and probe are phase-modulated with the same PRBS sequence, a correlation peak is generated within the microwire, activating a local Brillouin acoustic wave within a wire segment equal to the correlation peak length. This way, the method can selectively interrogate the Brillouin interaction taking place at each wire segment, enabling distributed measurements of the Brillouin gain spectrum with very high spatial resolution [3]. Specifically, the light from a laser diode $(\lambda=1551.7 \mathrm{~nm})$ is phase-modulated by a 1023 bit PRBS sequence. A PRBS bit duration of $250 \mathrm{ps}$ is used, corresponding to the correlation peak full-width at half-maximum (FWHM) of $\sim 13 \mathrm{~mm}$. Phase-modulated light is then split into pump and probe arms by using a 90/10 polarization-maintaining coupler. Light in the probe branch is amplitude-modulated at $\sim 7.9 \mathrm{GHz}$ to generate two sidebands with suppressed carrier [3]. A
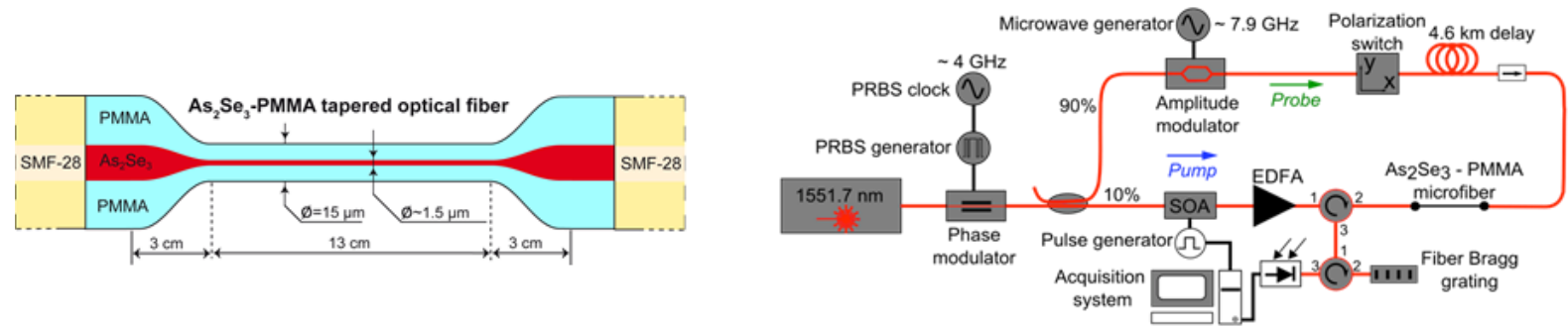

Figure 1: (a) Schematic of the polymer-coated chalcogenide optical microwire butt-coupled to single-mode fiber pigtails.

(b) Experimental setup of the phase-correlation distributed Brillouin spectrum mapping technique used to test the microwire. 
$4.6 \mathrm{~km}$-long single-mode fiber is used as a delay line to allocate a high-order correlation peak inside the microwire thus simply allowing the longitudinal scanning of the microwire by slightly varying the PRBS bit rate. With a sampling interval of $3.5 \mathrm{~mm}$ along the microwire, a spatial resolution of $9 \mathrm{~mm}$ could be achieved. In the pump arm, light is intensity-modulated by a semiconductor optical amplifier (SOA), generating pulses of $70 \mathrm{~ns}$. After SBS interaction, one probe sideband is selected by a tunable fiber Bragg grating and detected by a photo-receiver. The longitudinal scan has been conducted over a total length of $14 \mathrm{~cm}$ and the frequency scan has been restricted to the spectral range only covering the Brillouin gain spectrum of the tapered section.

Figure 2(a) shows the distributed Brillouin gain spectrum measured along the optical microwire. Based on the signal-to-noise ratio (SNR) of the measurements [4], we could calculate a frequency uncertainty of $1.3 \mathrm{MHz}$ along the tapered section. The mean value of the measured BFS is $7.924 \mathrm{GHz}$, which agrees with the theoretical value of $v_{B}=7.926 \mathrm{GHz}$, given by $v_{B}=2 n_{\text {eff }} V_{L} / \lambda$ [5], where $n_{\text {eff }}=2.733$ is the microwire effective refractive index and $V_{L}=2250 \mathrm{~m} \cdot \mathrm{s}^{-1}$ is the acoustic velocity in $\mathrm{As}_{2} \mathrm{Se}_{3}$ glass. For small diameter variation approximation, we assume that the effective refractive index calculated by using finite element software show a linear dependence of microwire diameter $d$ and can be defined as $n_{\text {eff }}=2.571+98.38 \times 10^{-3} \cdot d$. Taking into account a BFS standard deviation of $24.9 \mathrm{MHz}$, we found an excellent uniformity with a variation of $5 \%$. This corresponds to a wire diameter fluctuation of less than 50nm. Using the BFS profile shown in Fig. 2(a), we have estimated the beat length as being about $4 \mathrm{~cm}$, which yields a birefringence of $3.88 \times 10^{-5}$. Based on the $1.3 \mathrm{MHz}$ frequency uncertainty, the minimum diameter fluctuations that we can detect with this Brillouin measurement technique is $5 \mathrm{~nm}$ for a microwire diameter of $1.65 \mu \mathrm{m}$. Figure 2(b) shows the local Brillouin spectrum measured at the middle position of the microwire. A Brillouin gain linewidth of $51 \mathrm{MHz}$ can be observed, which is larger than the linewidth reported in chalcogenide fibers. This is due to the polymer cladding, which strongly absorbs the acoustic wave [5], reducing the peak gain and broadening the spectrum. Our measurement validates the microwire manufacturing based on the heat and brush technique, thus opening many other useful applications of optical microwires for future photonic technologies.
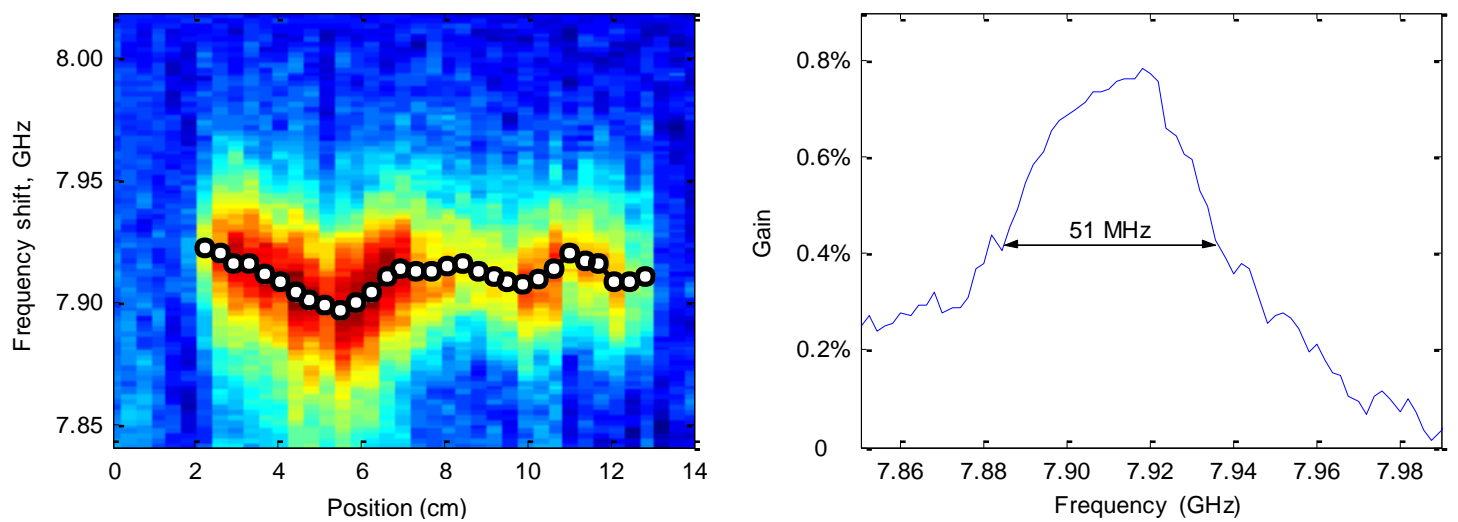

Figure. 2. Experimental results: (a) Distributed Brillouin gain spectrum measured along the $13 \mathrm{~cm}$-long chalcogenide microwire (white markers show the peak of the Brillouin resonance). (b) Local Brillouin gain spectrum in the middle of the microwire.

\section{Conclusion}

In conclusion, distributed measurements of the Brillouin gain spectrum inside an ultrathin chalcogenide microwire have been demonstrated using a phase-modulation correlation-domain technique. The longitudinal variations of the Brillouin frequency provide a reliable evaluation of the diameter uniformity along the microwire, highlighting that small-diameter tapered fibers made of chalcogenide glass can show uniformity better than $5 \%$.

This work was supported by the ANR OASIS (contract ANR-14-CE36-0005-01)

\section{References}

[1] G Brambilla, "Optical fibre nanowires and microwires: a review," J. Opt. 12(4), 043001 (2010).

[2] C. Baker and M. Rochette, "High nonlinearity and single-mode transmission in tapered multi-mode As2Se3-PMMA fibers," IEEE Photonics Journal 4(3), 960-969 (2012).

[3] A. Zadok, Y. Antman, N. Primerov, A. Denisov, J. Sancho, and L. Thévenaz, "Random-access distributed fiber sensing," Laser and Photonics Reviews 6(5), L1-L5 (2012).

[4] M. A. Soto and L. Thévenaz, "Modeling and evaluating the performance of Brillouin distributed optical fiber sensors," Opt. Express 21(25), 31347-31366 (2013).

[5] J-C. Beugnot et al., "Reduction and control of stimulated Brillouin scattering in polymer-coated chalcogenide optical microwires," Opt. Lett. 39(3), 482-485 (2014). 